\title{
Mindfulness training for smokers via web-based video instruction with phone support: a prospective observational study
}

\author{
James M Davis ${ }^{1,2,4,5^{*}}$, Alison R Manley ${ }^{1,3}$, Simon B Goldberg ${ }^{3}$, Kristin A Stankevitz ${ }^{1}$ and Stevens S Smith ${ }^{1,2}$
}

\begin{abstract}
Background: Many smokers are unable to access effective behavioral smoking cessation therapies due to location, financial limitations, schedule, transportation issues or other reasons. We report results from a prospective observational study in which a promising novel behavioral intervention, Mindfulness Training for Smokers was provided via web-based video instruction with telephone-based counseling support.

Methods: Data were collected on 26 low socioeconomic status smokers. Participants were asked to watch eight video-based classes describing mindfulness skills and how to use these skills to overcome various core challenges in tobacco dependence. Participants received eight weekly phone calls from a smoking cessation coach who provided general support and answered questions about the videos. On the quit day, participants received two weeks of nicotine patches.

Results: Participants were a mean of 40.5 years of age, smoked 16.31 cigarettes per day for 21.88 years, with a mean of 6.81 prior failed quit attempts. Participants completed a mean of 5.55 of 8 online video classes with a mean of 23.33 minutes per login, completed a mean of 3.19 of 8 phone coach calls, and reported a mean meditation practice time of 12.17 minutes per day. Smoking abstinence was defined as self-reported abstinence on a smoking calendar with biochemical confirmation via carbon monoxide breath-test under 7 parts per million. Intent-to-treat analysis demonstrated 7-day point prevalence smoking abstinence at 4 and 6-months post-quit of $23.1 \%$ and $15.4 \%$ respectively. Participants showed a significant pre- to post-intervention increase in mindfulness as measured by the Five-Factor Mindfulness Questionnaire, and a significant pre- to post-intervention decrease in the Anxiety Sub-scale of the Depression Anxiety and Stress Scale.
\end{abstract}

Conclusions: Results suggest that Mindfulness Training for Smokers can be provided via web-based video instruction with phone support and yield reasonable participant engagement on intervention practices and that intervention efficacy and mechanism of effect deserve further study.

Trial registration: ClinicalTrials.gov: NCT02164656, Registration Date June 13, 2014.

\section{Background}

Tobacco use is the number one cause of preventable morbidity and mortality in the US [1], has devastating health effects worldwide [2], but is notoriously difficult to treat [3]. Approximately 50\% of US smokers attempt smoking cessation each year [4], but discouragingly,

\footnotetext{
*Correspondence: james.m.davis@duke.edu

'University of Wisconsin School of Medicine and Public Health, Center for Tobacco Research and Intervention, Madison, USA

${ }^{2}$ Department of Medicine, University of Wisconsin School of Medicine and

Public Health, Madison, USA

Full list of author information is available at the end of the article
}

abstinence rates remain less than $5 \%$ in unassisted attempts $[5,6]$. Since the advent of US public awareness of health risks from smoking [7], many smokers who have been able to quit by using medications or other available therapies have already quit, leaving a population of smokers today that is more dependent [8], and more resistant to available therapies [9]. Smokers now are most highly represented within low socioeconomic status (SES) populations $[4,10]$ who often have limited access to effective therapies $[11,12]$. As the population of smokers becomes resistant to available therapies $[13,14]$ there is a 
growing need for new, effective therapies that can be made widely available, especially to disadvantaged populations [15].

Currently the most widely accessible smoking cessation therapies are telephonic smoking cessation programs or "quit lines," available to urban and rural smokers [16] in every US state [17]. Quit lines employ multiple therapeutic modalities including phone-based counseling, physician referral, mailed materials, subsidized pharmacotherapy [18], and web-based services $[19,20]$. Web-based services associated with quit lines may include written materials, short videos, interactive exercises, or access to online communities [21]. Web-based therapies have had a growing impact on low-SES smokers in the last decade, a change that is thought to be related to the development of wireless infrastructure in low SES regions [22], and adoption of smart phone use among disadvantaged populations $[23,24]$.

A meta-analysis of US quit line therapies reported mean biochemically confirmed 6-month abstinence rates of $12.7 \%$ and $14-22 \%$ overall with use of subsidized medications $[5,25,26]$. A study on a quit line in England showed similar biochemically confirmed 6-month postquit abstinence rates of $17.7 \%$ - 19.6\% [27]. A 2013 Cochrane review [28] on telephone-based counseling in smokers, including only studies reporting biochemically confirmed abstinence, noted that variation in abstinence rates was associated with the use of medications and the number of proactive phone calls completed. Studies on quit lines that relied on self-report alone to measure abstinence (no biochemical confirmation), have reported substantially higher abstinence rates (e.g. 29.9\% - 51.6\%) [29-31].

Efforts to develop new and more effective therapies for smokers have led to the development and testing of "mindfulness training" for treatment of tobacco dependence. Mindfulness has been described as "paying attention in a particular way: on purpose, in the present moment, and nonjudgmentally" [32]. Put another way, mindfulness means bringing greater awareness to and acceptance of presently occurring thoughts, feelings, or physical sensations, ultimately allowing for a less reflexive and more thoughtful response to experiences as they arise $[29,33]$. Over the last seven years there has been a small but growing body of evidence supporting mindfulness training as a smoking cessation therapy [34] with studies showing that mindfulness training is associated with decreases in smoking urges [30], stress [33], anxiety [35-37], and depression [38], known predictors of smoking relapse [39-42].

Studies on mindfulness training for smokers include an initial pilot study in 2007 [43], a randomized trial favorably comparing mindfulness training to Freedom from Smoking, (American Lung Association cessation program) [44], a randomized trial favorably comparing mindfulness training to quit line [34], a study showing positive effects of mindful "urge surfing" [45], a study that showed favorable comparison between Acceptance Commitment Therapy (ACT) and Cognitive Behavioral Therapy [46], a study on with favorable comparison between ACT (provided in individual therapy) and control [47], and others [48,49]. Although these face-to-face therapies demonstrate considerable promise for smokers, their public health impact is ultimately limited to treatment of patients who live near providing treatment centers. Currently there is only one notable report on a web-based mindfulness intervention for smokers - namely a study conducted by Bricker et al. in 2013 [50]. This study provided a web-based video instruction on Acceptance Commitment Therapy (ACT) combined with proactive phonecounseling calls. ACT videos and phone calls integrated training in mindfulness with other techniques to help smokers quit. This intervention showed self-reported smoking abstinence of $22.8 \%$ at 3 -months post-quit attempt, significantly higher than controls $(10.3 \%)(p=0.05)$ using Smokefree.gov, a widely used web-based intervention.

We report results of a pilot study on Mindfulness Training for Smokers Online (MTSO), a video-based intervention, developed for low SES populations cited above [44,51]. Up until now Mindfulness Training for Smokers (MTS) has only been used in face-to-face group interventions and has not been tested in a web-based video format with phone support. The primary objective of this study was to assess the feasibility of providing MTSO to smokers. Primary outcomes included completion of the five pre-quit video classes, the eight proactive phone calls, and the prescribed daily meditation and mindfulness practices. Also measured were changes in self-reported mindfulness, depression, anxiety and stress, and biochemically confirmed 4- and 24-weeks post-quit smoking abstinence.

\section{Methods \\ Recruitment procedure}

The study was funded through NIH/NIDA grant \#K23DA022471, approved by the University of Wisconsin Health Science Institutional Review Board, and registered by Clinicaltrials.gov on 6/13/2014, protocol \# NCT02164656. Participants were recruited over a 12month period through a larger "parent" study targeted to low SES neighborhoods within a mid-sized city. The parent study employed phone screening followed by an orientation visit with additional screening and enrollment for those qualified and interested. Inclusion and exclusion criteria in the parent study required that participants be at least 18 years of age, smoke five or more cigarettes per day, use no other tobacco products, claim high motivation to quit, and consume no more than four alcoholic drinks on four or more days per week. Further details on the parent study are provided in 
Davis et al. 2014 [49]. If individuals were excluded from the parent study during phone or orientation screening specifically due to scheduling conflicts, they were called back later to assess their potential eligibility for participation in the MTSO study. During phone screening for the MTSO study, the only additional requirement for participation was self-reported access to the Internet. During a face-to-face MTSO study orientation session, study procedures were described including payment of $\$ 30$ for attending each of the two face-to-face post-quit assessment visits (at 4 and 24 weeks post-quit attempt). If individuals decided to enroll in the study, they were provided with a user ID and password (written down for them), instructed in login procedures for the MTSO website, and asked to demonstrate the login procedure while at the study center. Potential participants were required to login to the MTSO website at home or at another off-site location to complete enrollment (a requirement employed to ensure that all study participants had Internet access).

\section{MTSO intervention}

MTSO is a web-based smoking cessation intervention that provides instruction in mindfulness techniques through eight weekly video classes (five pre-quit video classes, a quit day class, and two post quit classes). Video classes provide instruction in skills such as mindfulness meditation, mindful walking, mindful eating, and smokingspecific skills such as mindfulness of smoking triggers, urges, emotions, and thoughts (see Table 1). The course also includes access to an online manual (109 pages) that includes information identical to that in the videos but with greater depth for participants who wanted to learn more than they could from the video alone. Use of the manual, however, was not required or stressed. Finally, participants were provided with web-based audio

\begin{tabular}{ll} 
Table $\mathbf{1}$ Mindfulness training for smokers via web-based \\
video classes \\
\hline Week & Class activity \\
\hline 1 & Mindfulness and mindfulness meditation \\
2 & Mindful smoking and mindfulness of smoking triggers \\
3 & $\begin{array}{l}\text { Moments of mindfulness and mindfulness for emotions } \\
\text { and stressful situations }\end{array}$ \\
4 & $\begin{array}{l}\text { Mindful walking and mindfulness for urges and withdrawal } \\
5\end{array}$ \\
6 & Mindful eating and mindfulness for addictive thoughts \\
7 & Quit Day Retreat (start two weeks of nicotine patches) \\
8 & Mindfulness for relapse prevention
\end{tabular}

Note: The MTSO video classes provided training on how to use mindfulness to manage smoking relapse challenges. In addition, participants received access online to the MTSO Manual, Meditation CD and received weekly phone calls by an MTSO phone coach. recordings of two guided meditation practices (15 and 30 minutes). Materials used were identical to those used in the face-to-face intervention from the parent study except that the video, manual, and audio recordings were provided only in a web-based format, not in physical form. Participants were instructed to watch one video per week, talk to a phone coach each week, practice meditation daily with the audio recording, and use other mindfulness practices spontaneously throughout the day. The Phone Coach was trained in procedures through the three-day MTS Teacher-Training Course (provided for the face-to-face MTS intervention), and had no additional training in addiction therapy. Phone calls were made to participants once per week on a specified day and the call for that week was not repeated if the participant did not answer. Phone counseling calls were a maximum of 15 minutes and structured around core concepts and practices for each of the eight video-based classes. Calls were not scripted, but the Quit Coach was instructed to address each core issue from the prospective class and to provide "listening only" for "non-core" issues that the participant might wish to discuss. Fidelity to call procedures was assessed by the study PI who listened to two phone calls per class and provided feedback on core issues. Phone calls were not recorded. After five weeks of weekly videos with calls, participants were asked to engage in a self-directed "Quit Day Retreat" and attempt smoking cessation. The recommended schedule of activities for the Quit Day Retreat included five hours of gentle mindfulness practices alternating with rest; these included mindful meditation, mindful walking, mindful eating, and mindful drawing or yoga. Each practice was scheduled to last 30 minutes, and participants were encouraged to modify the schedule to fit their needs. On the day of the Quit Day Retreat participants began a 2-week course of nicotine patches with dosing of $21 \mathrm{mg}$ for $>10$ cigarettes/day and $14 \mathrm{mg}$ for $\leq 10$ cigarettes/ day. The phone coach made a call to participants on the Quit Day and made two weekly calls after that.

\section{Feasibility measures}

The following measures were employed to assess intervention feasibility: 1) phone call completion and length (recorded by the MTSO quit coach), 2) video completion (reported on Course Evaluation - covered only 5 pre-quit videos), and also by Quit Coach via phone report 3) website time (via a time-log function within the MTSO website), 4) minutes of daily meditation (via meditation calendar with daily minutes meditated recorded from Video Class 1 until the 4-week post-quit study visit, and 5) mindfulness practice (via Course Evaluation in which participants were asked to report the number of times per day that they engaged in various other mindfulness practices such as mindful walking, mindful eating, or moments of mindfulness). 


\section{Self-report measures}

In addition to these process measures, the following written surveys were obtained during baseline, 1-month post-quit, and 6-month post-quit assessment visits: 1) Demographics Questionnaire, a non-standardized questionnaire including information on demographics, smoking history, and Internet use (baseline only), 2) the Fagerstrom Test for Nicotine Dependence (FTND; only administered at baseline) [52], a six-item measure with internal consistency of $\alpha=.61$ and correlation with biological indices of heaviness of smoking, 3) the Five-Facet Mindfulness Questionnaire (FFMQ; all study visits), a 39question survey with internal consistency between $\alpha=.75$ and .91 [53-55] to assess mindfulness on five subscales ("observing," "describing," "acting with awareness," "nonjudging of inner experience," and "non-reactivity to inner experience"). In addition to FFMQ subscale scores, a composite score was derived from the total of subscale scores, as in previous research [55], and 4) the Depression Anxiety Stress Scales (DASS; all study visits), a 42-item measure with internal consistency of $\alpha=0.96,0.89$ and 0.93 for depression, anxiety, and stress, respectively $[56,57]$.

\section{Abstinence measures}

Data on smoking status was collected at three assessment visits: baseline, 4- and 24-weeks post-quit attempt. The primary outcome was 7-day point-prevalence abstinence by Timeline Follow-Back smoking calendar (TLFB) at 4- and 24-weeks post-quit day confirmed by a carbon monoxide (CO) breath test [58]. Abstinence was defined as a $\mathrm{CO}$ monitor reading below $7 \mathrm{ppm}$ (parts per million), a more stringent and contemporary standard used to minimize the possibility of false positive outcomes [59]. Determination of abstinence outcomes adhered to the intent-to-treat principle, such that failure to attend the 4- or 24-week assessment visits resulted in coding the participant as relapsed at that visit [60].

\section{Data analysis}

Paired $t$-tests were used to examine changes in test scores over time and logistic regression was used to examine the effects of continuous predictors on abstinence (e.g., changes in self-report measures, practice time). All analyses were conducted using SPSS (Version 21). A sample size of 26 was determined to be cost effective for a pilot study designed primarily at obtaining feasibility data.

\section{Results}

\section{Recruitment and demographics}

Over a 12-month period, 98 individuals declined participation in the parent study due to scheduling conflicts. Of these 98 called, 81 were successfully reached by phone and invited to attend the MTSO orientation (Figure 1). All 81 pre-participants stated that they had
Internet access ( 3 reported access through the public library) and all 81 were invited to the orientation. Of these, 45 attended the orientation, all signed consent, and all were given written instructions and a password to login to the MTSO website. Of these, 26 completed enrollment at their "home Internet site" by logging into the MTSO website. Enrolled participants had mean age of 40.5 years $(S D=38.48)$ and FTND $=3.92(S D=2.35)$. Most were Caucasian (88.5\%), female (57.7\%), and had education of high school or less $(53.8 \%)$ reflecting efforts to recruit low SES population (Table 2). Post-hoc analyses demonstrated that there were no significant differences on any demographic variable between participants enrolled in MTSO study and the parent study. There was also no significant differences on any demographic variable between those who attended the orientation and did vs. did not enroll in the intervention (by home login).

\section{Feasibility outcomes}

The mean number of pre-quit online video classes completed by self-report was 4.64 of $5(\mathrm{SD}=1.14$, range $=0-5)$. By another method, Quit Coach report of online video classes attended, the mean was of 5.55 of $8(\mathrm{SD}=2.48$, range $0-8$ ), with missing phone calls by Quit Coach coded as non-completion of the video classes. Mean logins to the MTSO website over the full intervention period was $8.05(S D=5.71$, range $=0-25)$, with mean time per site login of 23.33 minutes $(S D=15.36)$ (recorded through the website). The mean number of proactive phone coach calls completed was 3.19 of $8(S D=3.06$, range $=1-8)$. Mean reported meditation practice time was 12.17 minutes per day $(S D=8.15)$ (prescribed guided meditation recordings were 15 minutes/day for the first four weeks and 30 minutes/day until the 4-week study visit). Daily meditation time was not associated with abstinence $(p=0.71)$. Participants reported using informal mindfulness practices (e.g., moments of mindfulness, mindful walking, mindful eating, mindfulness of urges or triggers) an average of 5.0 times $(S D=6.15)$ per day up until the 4-week study visit. Intervention completion was defined as a self-reported quit attempt on the scheduled Quit Day. Using this definition "intervention completers" completed a minimum of 3 phone coach calls and 4 pre-quit video classes. Intervention completion rate was (20/26) $76.92 \%$ and was not associated with any demographic or baseline measure. Number of participants who used patches for the full two weeks was $12 / 26(46.15 \%)$. There were no reportable medication reactions and patch use was not significantly associated with abstinence.

\section{Abstinence rates}

Analysis of intent-to-treat samples showed biochemically confirmed 7-day point-prevalence smoking abstinence at 4- and 24-weeks post-quit attempt of 6/26 (23.08\%) and 


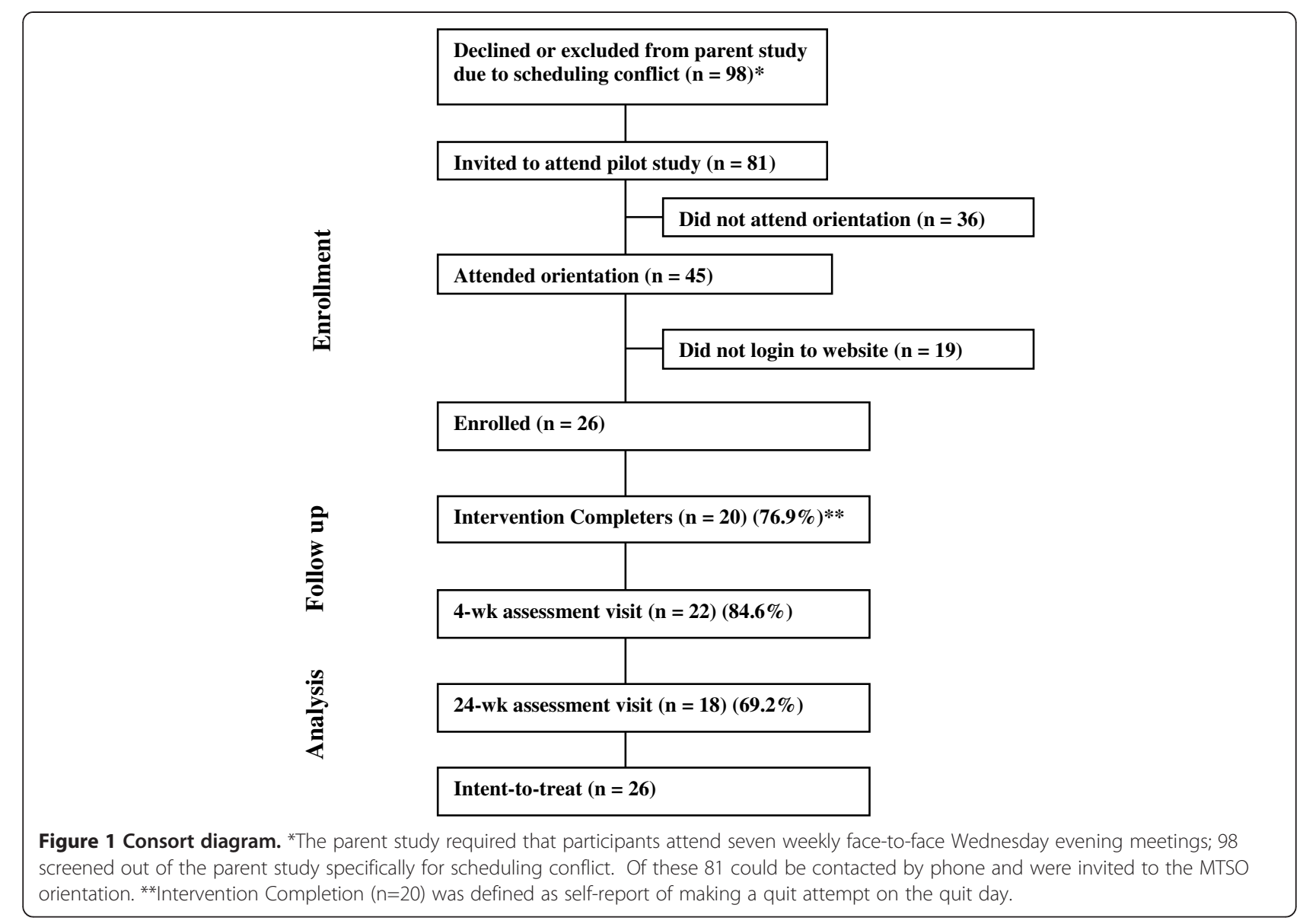

Table 2 Participant baseline characteristics

\begin{tabular}{ll}
\hline GENDER & \\
Male & $42.3 \%$ \\
Female & $57.7 \%$ \\
RACE/ETHNICIY & \\
American Indian & $0.0 \%$ \\
Asian & $0.0 \%$ \\
African-American & $3.8 \%$ \\
Caucasian & $88.5 \%$ \\
Other & $7.7 \%$ \\
Latino or Hispanic & $0.0 \%$ \\
EDUCATION & \\
Beyond high school & $46.2 \%$ \\
High school or less & $53.8 \%$ \\
Age & $\mathrm{M}=40.50(\mathrm{SD}=13.48)$ \\
No. of cigarettes/day & $\mathrm{M}=16.31(\mathrm{SD}=9.06)$ \\
No. of years smoked & $\mathrm{M}=21.88(\mathrm{SD}=13.55)$ \\
No. of quit attempts & $\mathrm{M}=6.81(\mathrm{SD}=7.05)$ \\
FTND & $\mathrm{M}=3.92(\mathrm{SD}=2.35)$ \\
\hline
\end{tabular}

*Recruitment and intervention materials were in English only.
4/26 (15.38\%), respectively. Other abstinence measures are provided in Table 3.

\section{Changes in mindfulness}

Paired samples $t$-tests were used to measure change from baseline to 4- and 24-week post-quit study visits on measures of mindfulness (FFMQ; Table 4). Participants demonstrated predicted significant increases on FFMQ observing from baseline $(M=3.41, S D=.84)$ to the 4-week post-quit visit $(M=3.96, S D=.40), t(17)=-3.07, p=.007$. This change persisted over time and was significant from baseline to the 24-week post-quit visit $(M=3.79, S D=.52), t$ $(17)=-2.11, p=.051$. Participants also showed predicted significant increases on FFMQ non-judging from baseline $(M=3.48, S D=.93)$ to the 24 -week post-quit visit $(M=$ $3.99, S D=.88), t(17)=-2.29, p=.035$. Additionally, participants demonstrated significant increases on the FFMQ composite score from baseline $(M=3.39, S D=.58)$ to 4 weeks post-quit $(M=3.66, S D=.21), t(17)=-2.10, p=.051$ and from baseline to the 24-weeks post-quit $(M=3.75$, $S D=.32), t(17)=-2.85, p=.011$. There were no significant associations between FFMQ composite score or subscales and smoking abstinence. 
Table 3 Abstinence rates at 4- and 24-weeks post-quit

\begin{tabular}{cl}
\hline Intent-to-treat analysis & $(\mathbf{n}=\mathbf{2 6})$ \\
4-week point prevalence & $23.1 \%$ \\
24-week point-prevalence & $15.4 \%$ \\
4-week continuous & $15.4 \%$ \\
24-week continuous & $7.7 \%$ \\
Completer analysis & $\mathbf{( n = 2 0 )}$ \\
4-week point prevalence & $30.0 \%$ \\
24-week point-prevalence & $20.0 \%$ \\
4-week continuous & $20.0 \%$ \\
24-week continuous & $10.0 \%$
\end{tabular}

Intent-to-Treat Analysis: Includes all subjects enrolled in the MTSO. Completer Analysis: Includes only those subjects who self-reported a quit attempt on the quit day.

Point Prevalence Abstinence: $\mathrm{CO}<7$ ppm plus no cigarettes for last 7 days on TLFB.

Continuous Abstinence: $\mathrm{CO}<7$ ppm plus no cigarettes on TLFB plus statement of no cigarettes since the Quit Day.

Those who did not attend the assessment visit were recorded as smoking every day.

\section{Changes in depression anxiety and stress}

Scores on the DASS demonstrated predicted significant decreases on the anxiety subscale from baseline $(M=.49$, $S D=.50)$ to 4 -week post-quit visit $(M=.31, S D=.32), t$ $(17)=2.12, p=.049$. Depression and stress subscales demonstrated change in the predicted direction (decrease over the intervention period), but changes were nonsignificant. There were no significant associations between DASS composite score or subscales smoking abstinence.

\section{Discussion}

Feasibility - intervention compliance

Compliance with the MTSO intervention was relatively good, with participants from low SES neighborhoods showing they were able to use the website, complete phone calls with the Phone Coach, and comply relatively well with daily meditation and mindfulness practices.
Completion of web-based course material was reassuring with participants reporting completion of 4.64 of 5 prequit videos, and the internal website log registering a mean of 8.05 total logins with 23.33 minutes per login. The mean number of calls completed with the Phone Coach was a bit lower at 3.19 of 8 possible calls. One reason phone call completion may have been somewhat low is that phone calls were made only one day per week and repeated attempts were not made to contact participants who missed calls. Research on quit lines suggests that there is a correlation between number of calls completed and abstinence rates [61], and that on average, smokers complete roughly half of the number of calls recommended [27].

\section{Feasibility - medication use}

There are a couple of reasons that may have lead to a lack of association between medication use and abstinence. The first is that while the behavioral treatment employed was quite intensive (mean completion of 4.64 of 5 pre-quit videos and 3.19 phone calls), the pharmacotherapy employed was relatively non-intensive - two weeks of nicotine patches - which though effective is less so than longer therapy (e.g., 12 weeks) [5]. It is also likely that the study was underpowered to demonstrate differences between compliant $(n=12)$ and noncompliant patch users $(n=14)$.

\section{Feasibility - practice time}

Adherence to daily meditation was modest but acceptable, with a mean of 12.17 minutes meditation practice per day. This is a lower rate of daily meditation practice than was found in Mindfulness Training for Smokers in a face-to-face format (21.6 minutes per day) [44]. Participants reported using other mindfulness practices (e.g., mindful walking, mindful eating, mindfulness of urges) a mean of 5.0 (SD 6.15) times per day, suggesting that

Table 4 Analysis of change in self-report measures over time

\begin{tabular}{llllll}
\hline Measures (n= 18) & Baseline mean (SD) & 4-weeks mean (SD) & 24-weeks mean (SD) & $\begin{array}{l}\boldsymbol{t} \text { statistic, sig Baseline } \\
\text { to 4-weeks }\end{array}$ & $\begin{array}{l}\boldsymbol{t} \text { statistic, sig Baseline } \\
\text { to 24-weeks }\end{array}$ \\
\hline FFMQ': Total score & $3.39(.58)$ & $3.66(.21)$ & $3.75(.32)$ & $t(17)=-2.10 p=.05$ & $t(17)=-2.85 p=.01^{*}$ \\
FFMQ: Non-judging & $3.48(.93)$ & $3.73(.66)$ & $3.99(.88)$ & $t(17)=-1.26 p=.23$ & $t(17)=-2.29 p=.04^{*}$ \\
FFMQ: Observing & $3.41(.84)$ & $3.96(.40)$ & $3.79(.52)$ & $t(17)=-3.07 p=.01^{*}$ & $t(17)=-2.11 p=.05$ \\
FFMQ: Non- reactivity & $3.12(.72)$ & $3.39(.57)$ & $3.43(.54)$ & $t(17)=-1.76 p=.10$ & $t(17)=-1.95 p=.07$ \\
FFMQ: Describing & $3.65(.68)$ & $3.68(.58)$ & $3.89(.61)$ & $t(17)=-.23 p=.82$ & $t(17)=-1.71 p=.11$ \\
FFMQ: Acting with awareness & $3.27(.88)$ & $3.49(.68)$ & $3.62(.48)$ & $t(17)=-1.26 p=.23$ & $t(17)=-1.81 p=.09$ \\
DASS': Total score & $0.66(.60)$ & $0.50(.27)$ & $0.39(.34)$ & $t(17)=1.24 p=.23$ & $t(17)=1.75 p=.10$ \\
DASS: Depression & $0.49(.69)$ & $0.33(.30)$ & $0.25(.28)$ & $t(17)=.92 p=.37$ & $t(17)=1.33 p=.20$ \\
DASS: Anxiety & $0.49(.50)$ & $0.31(.32)$ & $0.28(.32)$ & $t(17)=2.12 p=.05^{*}$ & $t(17)=1.71 p=.11$ \\
DASS: Stress & $1.02(.75)$ & $0.85(.54)$ & $0.65(.56)$ & $t(17)=.84 p=.41$ & $t(17)=1.97 p=.07$ \\
\hline
\end{tabular}

${ }^{1} \mathrm{FFMQ}=$ Five Facet Mindfulness Questionnaire; ${ }^{2}$ DASS $=$ Depression Anxiety Stress Scales.

*Values with asterisk are statistically significant $\left({ }^{*} p<.05\right)$. 
mindfulness practices were taught at least somewhat successfully through web-based instructional videos with phone support. The lack of association between meditation time and smoking cessation outcomes has been seen in other studies using mindfulness training for smokers $[43,49]$, and new data is now emerging to suggest that practice quality (self-reported on a practice quality measure) may be a better predictor than practice time of at least some psychiatric outcomes [62].

\section{Acquisition of mindfulness}

An important question to address when testing mindfulness training in a new format is whether participants are able to acquire mindfulness skills through this format. The most accepted secular training in the US is Mindfulness-Based Stress Reduction (MBSR) [30], which provides mindfulness training in face-to-face group format. This study suggests that participants did in fact acquire mindfulness skills as reflected in significant increases in pre- to post-intervention FFMQ subscales "observing" and "non-judging," and FFMQ composite scores. The increases in FFMQ subscales and composite provides support to the notion [34] that acquisition of mindfulness skills does not require face-to-face instruction, but might be successfully taught via web-based video instruction with phone support. It should be noted that the FFMQ has limitations typical of any self-report measure including susceptibility to social desirability bias [63] or "halo" effects [64]. To better assess mindfulness acquisition within this format, and reduce such potential bias, it would be helpful to compare MTSO to an active control in a randomized study design. The finding that FFMQ scores were not associated with abstinence may have been because mindfulness skills were not affecting smoking behavior, or may been due to insufficient power to detect this effect in a small study.

\section{Changes in anxiety, depression and stress}

Participants showed significant decreases in anxiety relative to baseline, as measured by scores on the DASS, which was promising given that research has implicated anxiety as a major cause of smoking relapse [65]. Participants also showed a drop in pre- to post-intervention depression and stress subscales and DASS composite score, but these changes were non-significant. A study by Goldberg et al. (2014) on Mindfulness Training for Smokers (in face-to-face group format) [66] showed decrease in self-reported pre- to post intervention DASS stress subscale and hair cortisol, suggesting that MTS in a face-to-face format does in fact lead to decreased stress. Statistically non-significant decreases in stress scores on DASS in this study suggests that MTSO has less robust effect on participants than MTS in a face-toface format, or that the study was insufficiently powered to demonstrate a significant change. The finding that DASS scores were not associated with abstinence may have been because changes in depression, anxiety or stress were not affecting smoking behavior, or may been due to insufficient power.

\section{Abstinence outcomes}

Biochemically confirmed abstinence rates of $23.1 \%$ at 1 month and $15.7 \%$ at 6 -month post-quit are on par with web-based quit line interventions cited in a recent metaanalysis [5], and even perhaps encouraging when targeting recruitment to a low SES population. Abstinence rates are similar to those found by Bricker et al. [50] who report a 3-month post-quit 30 day continuous abstinence rate of $22.8 \%$ (not-biochemically confirmed). Bricker's ACT intervention was similar in a number of ways; it was an 8-part program using web-based video instruction, and phone-support and provided training in a mindful approach to urges, emotions and thoughts.

\section{Limitations}

The major limitations of this feasibility study were it's small sample size and lack of a control group. In a pilot study such as this, findings on abstinence rates and selfreport measures can at most suggest the possibility of a therapeutic effect. Another potential confound in this study is that participants were recruited from a pool of individuals who reported scheduling conflicts. It is plausible that those who report scheduling conflicts were different in some respects from the smoking population as a whole, thus limiting the generalizability of results. For example, patients with busy schedules may be more active, have more demanding jobs and be more motivated to quit smoking. Additionally, the requirement of participants to have Internet access may have contributed to selection bias, perhaps selecting participants who were more advantaged and thus more likely to be compliant and maintain abstinence. The finding that there were no significant demographic differences between MTSO and parent study participants suggests that employment of inclusion criteria of scheduling conflicts and Internet access appear to have had only modest impact on sample selection. The fact that there were no demographic differences between those who came to the orientation and enrolled vs. did not enroll suggests that the requirement to login at home did not meaningfully impact sample selection. That being said, if larger sample were studied, significant differences between these groups may have been found.

\section{Conclusions}

This study evaluated a novel intervention that uses webbased video instruction and phone counseling to teach mindfulness skills to smokers. Such an intervention has 
the potential for large-scale web-based dissemination and could conceivably be used as a complementary therapy by a tobacco quit line. If MTSO were used along with other quit line treatments, it could potentially lead to higher abstinence rates in quit line callers. Because MTSO functions as a video-based intervention, it might conceivably be provided to a wide population at minimal expense. Even if only a modest portion of the smoking population were responsive to web-based mindfulness training, it could have a meaningful public health impact due to the wide accessibility of the Internet. Given the promising feasibility findings in this study, but considerable limitations due to small sample size and lack of control, we suggest that web-based mindfulness training for smokers would appear to merit further research.

\section{Competing interests}

There was no funding from tobacco, alcohol, pharmaceutical or gaming industries, and no connection between any researcher in this study and these industries. Authors in this study have no financial conflict of interest arising from involvement with organizations that seek to provide help with or promote recovery from addiction.

\section{Authors' contributions}

$J M D$, Procured NIH funding, MTSO intervention design, study design, IRB proposal, lab PI, was primary manuscript authorship. ARM, Study coordinator, data management, data analysis, IRB interactions, subject management, manuscript preparation. SBG, Study design, data analysis, manuscript preparation. KAS, Participant management, manuscript preparation. SSS, Senior research oversight, data analysis, manuscript preparation. All authors read and approved the final manuscript.

\section{Acknowledgments}

We would like to thank Kelly Bodoh, Mike Fiore, Doug Jorenby, Wendy Theobald, Hillary Merry, Andrew Sandgren, Paul Kohn, and Allison Couillard for their work on this research.

\section{Funding}

This research was supported by the National Institutes on Drug Abuse; grant \# K23DA022471.

\section{Author details}

${ }^{1}$ University of Wisconsin School of Medicine and Public Health, Center for Tobacco Research and Intervention, Madison, USA. ²Department of Medicine, University of Wisconsin School of Medicine and Public Health, Madison, USA. ${ }^{3}$ Department of Counseling Psychology, University of Medicine, Wisconsin, Madison, USA. ${ }^{4}$ Duke Center for Smoking Cessation, 2424 Erwin Road, Suite 201, Durham, NC 27705, USA. ${ }^{5}$ Department of Medicine, Duke University School of Medicine, Durham, USA.

Received: 9 May 2014 Accepted: 16 March 2015

Published online: 29 March 2015

\section{References}

1. Centers for Disease Control and Prevention. Smoking-attributable mortality, years of potential life lost, and productivity losses-United States, 2000-2004. MMWR Morb Mortal Wkly Rep. 2008;57(45):1226-8.

2. MacKay J, Eriksen M. The tobacco atlas. Brighton, UK: Myriad Editions; 2002.

3. U.S. Department of Health and Human Services. How tobacco smoke causes disease: the biology and behavioral basis for smoking-attributable disease: a report of the Surgeon General. Atlanta, GA: U.S. Department of Health and Human Services, Centers for Disease Control and Prevention, National Center for Chronic Disease Prevention and Health Promotion, Office on Smoking and Health; 2010.

4. Centers for Disease Control and Prevention. Quitting smoking among adults - United States 2001-2010. MMWR. 2011;60(44):1513-9.
5. Fiore MC, Jaen CR, Baker TB, Bailey WC, Benowitz N, Curry SJ, et al. Treating tobacco use and dependence: 2008 update. Rockville, MD: U.S. Department of Health and Human Services, U.S. Public Health Service; 2008.

6. Hughes JR, Keely J, Naud S. Shape of the relapse curve and long-term abstinence among untreated smokers. Addiction. 2004;99(1):29-38.

7. United States Surgeon General's Advisory Committee on Smoking. Smoking and health: report of the advisory committee to the Surgeon General of the public health service. Washington DC: US Government Printing Office; 1964.

8. Cokkinides V, Bandi P, McMahon C, Jemal A, Glynn T, Ward E. Tobacco control in the United States-recent progress and opportunities. CA Cancer J Clin. 2009;59(6):352-65.

9. Irvin JE, Hendricks PS, Brandon TH. The increasing recalcitrance of smokers in clinical trials II: pharmacotherapy trials. Nicotine Tob Res. 2003;5(1):27-35.

10. Hiscock R, Bauld L, Amos A, Fidler JA, Munafò M. Socioeconomic status and smoking: a review. Ann N Y Acad Sci. 2012;1248(1):107-23.

11. Bandi P, Cokkinides VE, Virgo KS, Ward EM. The receipt and utilization of effective clinical smoking cessation services in subgroups of the insured and uninsured populations in the USA. J Behav Health Serv Res. 2012;39(2):202-13.

12. Mussulman L, Ellerbeck EF, Cupertino AP, Preacher KJ, Spaulding R, Catley D, et al. Design and participant characteristics of a randomized-controlled trial of telemedicine for smoking cessation among rural smokers. Contemp Clin Trials. 2014;38(2):173-81.

13. Orleans $C T$. Increasing the demand for and use of effective smoking-cessation treatments reaping the full health benefits of tobacco-control science and policy gains-in our lifetime. Am J Prev Med. 2007;33(6 Suppl):S340-8.

14. Warner KE, Burns DM. Hardening and the hard-core smoker: concepts, evidence, and implications. Nicotine Tob Res. 2003;5(1):37-48.

15. Brandon TH. Behavioral tobacco cessation treatments: yesterday's news or tomorrow's headlines? J Clin Oncol. 2001;19(18 Suppl):64S-8.

16. Cummins SE, Hebert KK, Anderson CM, Mills JA, Zhu SH. Reaching young adult smokers through quitlines. Am J Public Health. 2007;97(8):1402-5.

17. North American Quitline Consortium. All quitline facts: an overview of the NACQ 2009 Annual Survey of Quitlines. 2010.

18. Ossip-Klein DJ, McIntosh S. Quitlines in North America: evidence base and applications. Am J Med Sci. 2003;326(4):201-5.

19. Cummins SE, Bailey L, Campbell S, Koon-Kirby C, Zhu SH. Tobacco cessation quitlines in North America: a descriptive study. Tob Control. 2007;16 Suppl 1:i9-15.

20. North American Quitline Consortium. U.S. quitlines: internet-based services. In: 2008 NACQ annual survey. 2008.

21. Bock BC, Graham AL, Whiteley JA, Stoddard JL. A review of web-assisted tobacco interventions (WATIs). J Med Internet Res. 2008;10(5):e39.

22. Raine L, Reddy P, Bell P. Rural areas and the internet. In: Digital divide. 2004.

23. Smith A. Mobile access 2010. Retrieved. 2010;13:2011.

24. Smith A. Cell Internet use 2012. Pew internet and american life project. 2012.

25. McAlister AL, Rabius V, Geiger A, Glynn TJ, Huang P, Todd R. Telephone assistance for smoking cessation: one year cost effectiveness estimations. Tob Control. 2004;13(1):85-6.

26. Tomson T, Helgason AR, Gilljam H. Quitline in smoking cessation: a costeffectiveness analysis. Int J Technol Assess Health Care. 2004;20(04):469-74.

27. Ferguson J, Docherty G, Bauld L, Lewis S, Lorgelly P, Boyd KA, et al. Effect of offering different levels of support and free nicotine replacement therapy via an English national telephone quitline: randomised controlled trial. BMJ. 2012;344:e1696.

28. Civljak M, Stead LF, Hartmann-Boyce J, Sheikh A, Car J. Internet-based interventions for smoking cessation. Cochrane Database Syst Rev. 2013;7:Cd007078.

29. Segal Z, Williams JW, Teasdale J. Mindfullness-based cognitive therapy for depression: a new approach to preventing relapse. New York: The Guilford Press; 2002.

30. Westbrook C, Creswell JD, Tabibnia G, Julson E, Kober H, Tindle HA. Mindful attention reduces neural and self-reported cue-induced craving in smokers. Soc Cogn Affect Neurosci. 2011;8(1):73-84.

31. Grossman P, Niemann L, Schmidt S, Walach H. Mindfulness-based stress reduction and health benefits. A meta-analysis. J Psychosom Res. 2004;57(1):35-43.

32. Kabat-Zinn J. Wherever you go, there you are: mindfulness meditation in everyday life. New York: Hyperion; 1994.

33. Kabat-Zinn J. Full catastrophe living. New York: Dell Publishing; 1990.

34. Davis JM, Goldberg SB, Anderson MC, Manley AR, Smith SS, Baker TB. Randomized trial on mindfulness training for smokers targeted to a disadvantaged population. Subst Use Misuse. 2014;49(5):571-85. 
35. Creswell JD, Way BM, Eisenberger NI, Lieberman MD. Neural correlates of dispositional mindfulness during affect labeling. Psychosom Med. 2007;69(6):560-5.

36. Hofmann SG, Sawyer AT, Witt AA, Oh D. The effect of mindfulness-based therapy on anxiety and depression: a meta-analytic review. J Consult Clin Psychol. 2010;78(2):169-83.

37. Koszycki D, Benger M, Shlik J, Bradwejn J. Randomized trial of a meditationbased stress reduction program and cognitive behavior therapy in generalized social anxiety disorder. Behav Res Ther. 2007;45(10):2518-26.

38. Teasdale JD, Segal Z, Williams JM. How does cognitive therapy prevent depressive relapse and why should attentional control (mindfulness) training help? Behav Res Ther. 1995;33(1):25-39.

39. Leventhal AM, Zvolensky MJ. Anxiety, depression, and cigarette smoking: a transdiagnostic vulnerability framework to understanding emotion-smoking comorbidity. Psychological Bull. 2014;141(1):176-212.

40. Leventhal AM, Piper ME, Japuntich SJ, Baker TB, Cook JW. Anhedonia, depressed mood, and smoking cessation outcome. J Consult Clin Psychol. 2014;82(1):122.

41. Piper ME, Cook JW, Schlam TR, Jorenby DE, Baker TB. Anxiety diagnoses in smokers seeking cessation treatment: relations with tobacco dependence, withdrawal, outcome and response to treatment. Addiction. 2011;106(2):418-27.

42. Piper ME, Smith SS, Schlam TR, Fleming MF, Bittrich AA, Brown JL, et al. Psychiatric disorders in smokers seeking treatment for tobacco dependence: relations with tobacco dependence and cessation. J Consult Clin Psychol. 2010;78(1):13-23.

43. Davis JM, Fleming MF, Bonus KA, Baker TB. A pilot study on mindfulness based stress reduction for smokers. BMC Complement Altern Med. 2007;7:2.

44. Brewer JA, Mallik S, Babuscio TA, Nich C, Johnson HE, Deleone CM, et al. Mindfulness training for smoking cessation: results from a randomized controlled trial. Drug Alcohol Depend. 2011;110(1-2):72-80.

45. Bowen S, Marlatt A. Surfing the urge: brief mindfulness-based intervention for college student smokers. Psychol Addict Behav. 2009;23(4):666.

46. Hernández-López M, Luciano MC, Bricker JB, Roales-Nieto JG, Montesinos F. Acceptance and commitment therapy for smoking cessation: a preliminary study of its effectiveness in comparison with cognitive behavioral therapy. Psychol Addict Behav. 2009;23(4):723.

47. Gifford EV, Kohlenberg BS, Hayes SC, Pierson HM, Piasecki MP, Antonuccio DO, et al. Does acceptance and relationship focused behavior therapy contribute to bupropion outcomes? A randomized controlled trial of functional analytic psychotherapy and acceptance and commitment therapy for smoking cessation. Behav Ther. 2011;42(4):700-15.

48. Davis J, Mills D, Stankevitz K, Manley A, Majeskie M, Smith S. Pilot randomized trial on mindfulness training for smokers in young adult binge drinkers. BMC Complement Altern Med. 2013;13(1):215.

49. Davis JM, Manley AR, Goldberg SB, Smith SS, Jorenby DE. Randomized trial comparing mindfulness training for smokers to a matched control. J Subst Abuse Treat. 2014;47(3):213-21.

50. Bricker J, Wyszynski C, Comstock B, Heffner JL. Pilot randomized controlled trial of web-based acceptance and commitment therapy for smoking cessation. Nicotine Tob Res. 2013;15(10):1756-64.

51. Davis JM, Manley AR, Goldberg SB, Smith SS, Jorenby DE. Randomized trial comparing mindfulness training for smokers to a matched control. J Subst Abuse Treat. doi: 10.1016/j.jsat.2014.04.005.

52. Heatherton TF, Kozlowski LT, Frecker RC, Fagerstrom KO. The fagerstrom test for nicotine dependence: a revision of the fagerstrom tolerance questionnaire. Br J Addict. 1991;86(9):1119-27.

53. Baer RA, Smith GT, Hopkins J, Krietemeyer J, Toney L. Using self-report assessment methods to explore facets of mindfulness. Assessment. 2006;13(1):27-45.

54. Baer RA, Smith GT, Lykins E, Button D, Krietemeyer J, Sauer S, et al. Construct validity of the five facet mindfulness questionnaire in meditating and nonmeditating samples. Assessment. 2008;15(3):329-42.

55. Lykins ELB, Baer RA. Psychological functioning in a sample of long-term practitioners of mindfulness meditation. J Cogn Psychother. 2009;23(3):226-41.

56. Brown TA, Chorpita BF, Korotitsch W, Barlow DH. Psychometric properties of the Depression Anxiety Stress Scales (DASS) in clinical samples. Behav Res Ther. 1997;35(1):79-89.

57. Lovibond SH, Lovibond PF. Manual for the Depression Anxiety Stress Scales. 2nd ed. Sydney: Psychology Foundation; 1995.
58. Brown RA, Burgess ES, Sales SD, Whiteley JA, Evans DM, Miller IW. Reliability and validity of a smoking timeline follow-back interview. Psychol Addict Behav. 1998;12(2):101-12.

59. Middleton ET, Morice AH. Breath carbon monoxide as an indication of smoking habit. Chest. 2000;117(3):758-63.

60. Schlomer GL, Bauman S, Card NA. Best practices for missing data management in counseling psychology. J Couns Psychol. 2010;57(1):1-10.

61. Stead L, Perera R, Lancaster T. Telephone counselling for smoking cessation. Cochrane Database Syst Rev. 2006;3, CD002850.

62. Goldberg SB, Del Re AC, Hoyt WT, Davis JM. The secret ingredient in mindfulness interventions? A case for practice quality over quantity. J Couns Psychol. 2014;61(3):491-7.

63. Van de Mortel TF. Faking it: social desirability response bias in self-report research. Aust J Adv Nurs. 2008;25(4):40.

64. Hoyt WT. Rater bias in psychological research: when is it a problem and what can we do about it? Psychol Methods. 2000;5(1):64-86.

65. Baker TB, Piper ME, McCarthy DE, Majeskie MR, Fiore MC. Addiction motivation reformulated: an affective processing model of negative reinforcement. Psychol Rev. 2004;111(1):33-51.

66. Goldberg SB, Manley AR, Smith SS, Greeson JM, Russell E, Van Uum S, et al. Hair cortisol as a biomarker of stress in mindfulness training for smokers. J Altern Complement Med. 2014;20(8):630-4.

\section{Submit your next manuscript to BioMed Central and take full advantage of:}

- Convenient online submission

- Thorough peer review

- No space constraints or color figure charges

- Immediate publication on acceptance

- Inclusion in PubMed, CAS, Scopus and Google Scholar

- Research which is freely available for redistribution 